\title{
Assessment of the environmental organization development strategy
}

\author{
Elena Petrova ${ }^{1}$, Igor Petrov $^{1, *}$, Tatyana Shivrina $^{2}$, and Tamara Narezhnaya ${ }^{3}$ \\ ${ }^{1}$ Vyatka State University, Moskovskaya str., 36, Kirov, 610000, Russia \\ ${ }^{2}$ Vyatka State Agrotechnological University, Oktyabrsky avenue, 133, Kirov, 610017, Russia \\ ${ }^{3}$ Moscow State University of Civil Engineering, 26, Yaroslavskoye Shosse, 109377, Moscow, Russia
}

\begin{abstract}
Assessment of feasibility of applying the chosen organization development strategy should be based on assessment of its effectiveness. The proposed methods for assessing the development strategy provide for defining indexes that, in accordance with set strategic goals, should take into account an entire set of target strategic indexes. The methodology consists in calculating integral indexes characterizing achievement of set strategic goals. As such indexes, which take into account key strategic parameters, estimated development indexes and assessments of the organization sustainable development potential are proposed. These indexes should be used as an indicator of the development strategy and achievement of strategic goals.
\end{abstract}

\section{Introduction}

Strategic management plays an essential role in ensuring effective economic development of the organization by improving the mechanism for achieving long-term development goals of these organizations on the basis of real assessment of their capabilities and production potential.

Organization development is a process of positive changes in economic activity, aimed at using the potential of the organization and further strengthening it in order to increase competitiveness and business activity. The potential of the organization is a set of opportunities for implementation of economic activities, determined by resources at the disposal of the organization [1].

One of the ways of development of organizations is introduction of fundamental principles on which strategic management of organizations should be based. These include the following:

-the principle of scientific logic and analytical foresight;

-the principle of continuous interaction of the internal environment of the organization with the external environment of its functioning;

-the principle of flexibility in strategic management;

-the principle of technological compliance and improving management of organizations;

-the principle of adequacy of the strategy and tactics of managing organizations;

-the principle of alternative strategic management;

\footnotetext{
*Corresponding author: soft.rosko@mail.ru
} 
- the principle of control.

The process of strategic management of organizations is management of their potential through formation of a system of targeted decisions that ensure development, performance assessment and implementation of the economic development strategy. We have identified the main stages of the process of forming the strategy and the algorithm for strategic management of organizations, proposed for theoretical and applied purposes of rationalizing management. This process can be carried out in organizations in the following main stages:

-determining the time horizon for formation of the organization strategy;

-assessment of the external and internal environment of the organization functioning and diagnostics of its strategic potential;

-determining the strategic position of the organization;

-determining strategic goals of the organization;

-determining target strategic indicators;

- making key strategic decisions;

-assessing the development strategy;

-providing the process of implementing the strategy; monitoring implementation of the strategy.

Assessment of feasibility of the organization development strategy, in our opinion, should be the final stage in the process of strategy formation in the organization strategic management system. This assessment, first of all, should be based on the most complete and reliable information contained in the strategic development plan of the organization and consists in diagnosing consequences of the developed strategy for its economic development.

By now there is practically no unified methodologically optimal approach to assessing effectiveness of strategic decision-making based on a single (integral) indicator. In modern conditions organizations operate in a continuously changing external business environment [2]. For example, if the flexible approach, on the one hand, based on solving some problems arising from operational and current, formed for several months or quarters in advance, targets can be applied for small and medium-sized organizations, then for large organizations which build their strategic plans for many years, this approach is better not to apply.

An important and basic criterion for assessing the development strategy in the system of strategic management of the organization activities should be achievement of the organization of its strategic goals [3].

Formation of key elements of the organization strategic management is based on the results of strategic assessment and strategic diagnostics, which are the most important components of strategic management. The concept of strategic management requires the presence of an analytical framework in all management functions. Strategic assessment is a process of determining the influence of factors of the external and internal environment of functioning on effectiveness of the organization in order to identify its strengths and weaknesses, as well as existing opportunities and threats.

Strategic diagnostics is a tool for assessing the current strategy and identifying consequences of implementation of the strategy, including assessing its effectiveness. Strategic diagnostics identifies opportunities for implementing the adopted strategy, and whether this will lead to achievement of the goals set by the organizations. Strategic management decisions based on the results of strategic assessment and diagnostics enable organizations to fulfill their mission and achieve their strategic goals.

An important point in the process of strategic management of organizations is the timely identification of strategic problems through the use of methods of strategic diagnostics. One of these methods is the use of economic and mathematical modeling.

The purpose of building the model was to study the influence of various factors on the 
potential of sustainable development of the organization. At the same time, the index of return on assets was chosen as an effective index. The assets of the organization in accordance with Russian legislation represent resources owned or controlled by the organization as a result of previous economic activities from which it is expected to receive economic benefits in the future. These economic benefits are associated with increased income and profits from the use of these assets (property). At the same time, assessment of profitability of property is an index that characterizes the sustainability of the organization development, since it reflects economic benefits from the use of this potential and predetermines the possibility of economic development. [3].

The annual increase in economic potential characterizes the organization as developing

Therefore, an important task in identifying the potential for sustainable development of the organization is to determine those parameters of an increase in profitability of assets that provide real growth and minimize risks. The return on assets is recommended to be assessed based on net profit, since it is the basis for increasing potential when capitalizing in owners' equity.

So, as factors of the model, indexes that affect the potential for sustainable development of the organization and characterize the financial stability, financial solvency and business activity of the organization were selected.

The initial data for the study were statistical data on the main financial and economic indexes. It should be noted that at different periods of time the same organization is considered as a separate organization (observation). Thus, a sample of 55 observations was formed.

The need to cluster the initial data is due to the lack of a priori information on the distribution of the general set of observations. Therefore, to classify organizations into groups homogeneous in terms of sustainable development potential, capabilities of cluster analysis are used.

Thus, the initial data is a $55 \times 17$ matrix X, i.e. values of 55 organizations on 17 grounds.

Initial observations were clustered using the K-means method. The use of this particular clustering method made it possible to split the existing sample of organizations into a given number of groups (three groups) of financial condition and sustainable development potential.

Division of organizations into only two groups of development potential (high and low) would be difficult, since under the current conditions, most organizations experiencing financial difficulties continue to function and it is impossible to determine their financial condition unequivocally as favorable or close to bankruptcy. That is why a "middle" group of organizations is needed. Four or more classes under given conditions lead to a small number of groups and, as a consequence, to a weak difference between them. Cluster analysis was performed using the Cluster Analisys module in Statistica 6.0.

Clustering is based on analysis of variance, which tests the hypothesis of equality of variance between clusters and within them. If the hypothesis is rejected (i.e. it is assumed that the variances are equal), then the resulting classification is meaningless, since the data are statistically homogeneous and cannot be divided into different groups.

The variance table (Analysis of Variance tab) allows to evaluate the effectiveness of the classification carried out using three clusters. Factors insignificant for clustering were consistently excluded.

Thus, the calculated values of the significance level (less than 0.05) allow to accept the hypothesis of inequality of variances, i.e. dividing the initial set of observations by 11 factors into 3 groups is reasonable.

To assess the differences between the clusters from each other, the average values of attributes were calculated for each cluster. Euclidean distance was used as a metric. Table 1 
shows the Euclidean distances (below the diagonal) and the squares of the Euclidean distances (above the diagonal) between the centers of the resulting clusters.

The obtained results indicate a significant difference between the obtained groups.

Table 1. Euclidean distances and squares of the Euclidean distances between the centers of the resulting clusters.

\begin{tabular}{|c|c|c|c|}
\hline & Cluster 1 & Cluster 2 & Cluster 3 \\
\hline Cluster 1 & 0 & 0.862553 & 2.905350 \\
\hline Cluster 2 & 0.928737 & 0 & 0.872315 \\
\hline Cluster 3 & 1.704509 & 0.933978 & 0 \\
\hline
\end{tabular}

Thus, based on the results of the conducted cluster analysis, the initial sample of 55 organizations was divided into three groups of the organization sustainable development potential:

-organizations with high potential for sustainable development of the organization;

-organizations with low potential for sustainable development of the organization;

- high-risk organizations that are in a financial crisis, insolvent or with low solvency, with a real prospect of bankruptcy, that is, practically without the potential for sustainable development of the organization.

As a result, the first group included 17 organizations, the second -23 , and the third -15 organizations.

The results of the conducted clustering served as a priori information on the potential for sustainable development of the studied organizations.

As it was mentioned above, the potential for sustainable development of the organization can be characterized by the following groups of factors: indexes of financial stability, assessment of property status, solvency (liquidity), business activity, and profitability. There is a functional dependence between some of them, due to the fact that they are all based on a single accounting report. This dependence was investigated and those main financial indexes were selected, between which it is not observed [4]. In addition, to build the model, we selected factors between which the correlation coefficient is less than 0.5 (i.e. the linear relationship between which is weak or practically absent).

As a result, using the step-by-step exclusion method, a significant model was obtained with the following factors affecting the return on assets: the autonomy ratio, the asset turnover ratio, the equity capital mobility ratio, and the profitability of spending [4].

Based on the results of the obtained correlation and weighting coefficients, the following model of the organization sustainable development potential was obtained:

$$
P_{a}=-23,34+16,56 K_{l}+8,29 K_{2}+0,52 K_{3}+0,68 K_{4}
$$

where

$P_{a}$ - the coefficient of return on assets;

$K_{l}$ - the coefficient of autonomy;

$K_{2}$ - the coefficient of the asset turnover ratio;

$K_{3}$ - the coefficient of mobility of equity capital;

$K_{4}$ - the coefficient of profitability of spending.

To use the model to classify organizations, boundary conditions were defined for each group, i.e. the coordinates of the centroids of each group are substituted into the resulting model (the average values of the features for each group). This allows determining the boundaries of the interval for each group; when the values of the regression model for a particular observation fall into it, then this observation can be assigned to the corresponding group.

In this case, zones of uncertainty inevitably arise, which are sometimes called "gray 
zones" (for example, the intervals of neighboring groups intersect, or some part of the number line is not occupied by any of the intervals).

In this case, assignment of the observation to any group is difficult. With the introduction of zones of uncertainty, the division of the number line into zones is obtained, when values fall into them we can speak of an intermediate position when attributing the organization to a certain class.

Depending on the calculated return on assets $\left(\mathrm{R}_{\mathrm{a}}\right)$, the organization sustainable development potential is assessed:

- if $\mathrm{R}_{\mathrm{a}}>14,805$, then the organizations have a high potential for sustainable development;

- if 14,805 $>R_{a}>9,439$, then the organizations occupy an intermediate position between high and low potential for sustainable development;

- if $9,439>R_{a}>-1,078$, then the organizations have low potential for sustainable development;

- if $-1,078>R_{a}>-8,915$, then the organizations occupy an intermediate position between low potential for sustainable development and its absence;

- if $R_{a}<-8,915$, then the financial state of the organization is in crisis and there is no sustainable development potential.

This model allows determining the potential for sustainable development of the organization in the process of implementing the strategy of economic development. In addition, the application of this model enables the management personnel involved in strategic control to timely respond to negative changes in the development of the organization business processes and take preventive measures to neutralize them.

Assessment of feasibility of applying the chosen strategy, of course, should be based on assessment of its effectiveness. This assessment, in our opinion, should be the final stage in the process of forming the strategy in the system of strategic management of development of activities of the organization.

The process of assessing the development strategy in the system of strategic management of activities of the organization, in our opinion, should consist of the following main stages, shown in Figure 1:

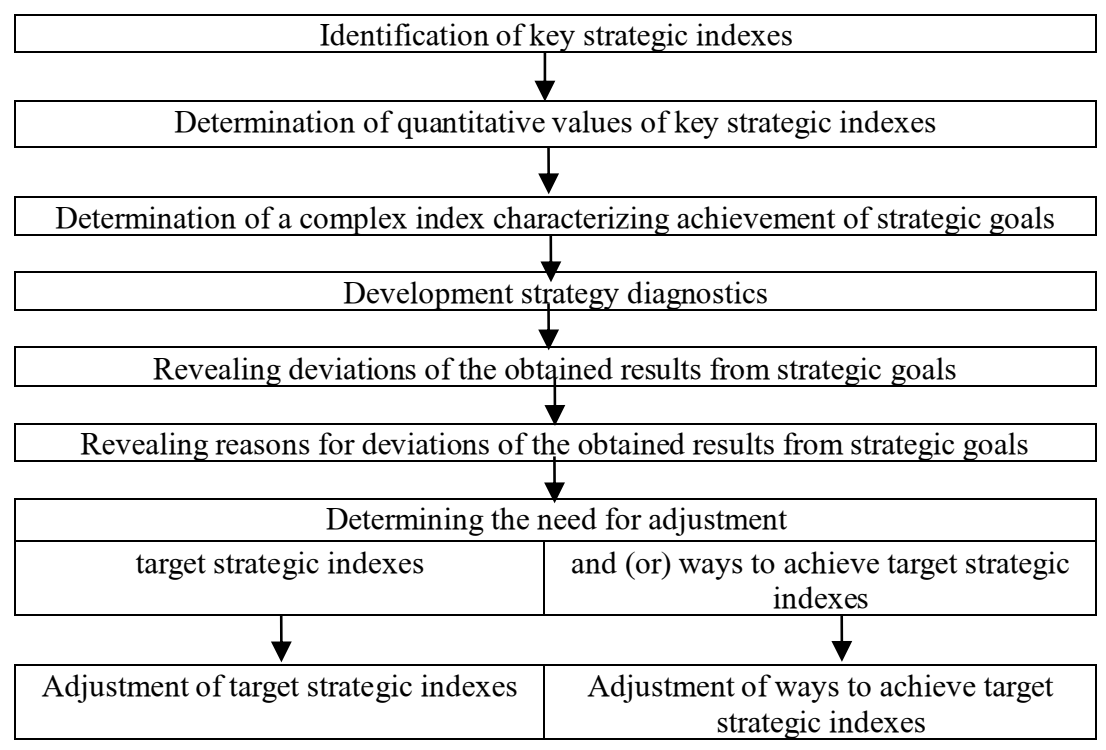

Fig .1. The process of assessing the development strategy of the organization.

It is necessary to consider the stages of the process of assessing the development 
strategy of the organization in more detail:

1. Identification of key strategic indexes. This stage consists in determining an entire set of key strategic indexes;

2. Determination of absolute values of key strategic indexes. It means quantitative determination of values of relevant strategic indexes;

3. Determination of a complex index characterizing achievement of strategic goals. At this stage, a complex index is chosen that takes into account an entire set of key strategic indexes as much as possible;

4. Diagnostics of effectiveness of strategy implementation is a process of determining the value of a complex index and making a diagnosis related to achievement of strategic goals;

5. Identification of deviations of the obtained results from the strategic goals should be formalized, i.e. their quantitative assessment, in addition, the nature of the identified deviations should be determined;

6. Identification of reasons for deviations of the results from the strategic goals. This stage consists in determining the reasons for deviations, both formalized and nonformalized;

7. Making decisions on the need to adjust target strategic indexes and (or) ways to achieve them, or the absence of such a need, if the complex index corresponds to the goals of strategic development.

8. Adjustment of target strategic indexes and ways to achieve them.

The development strategy assessment process should be built in accordance with the principles shown in Figure 2:

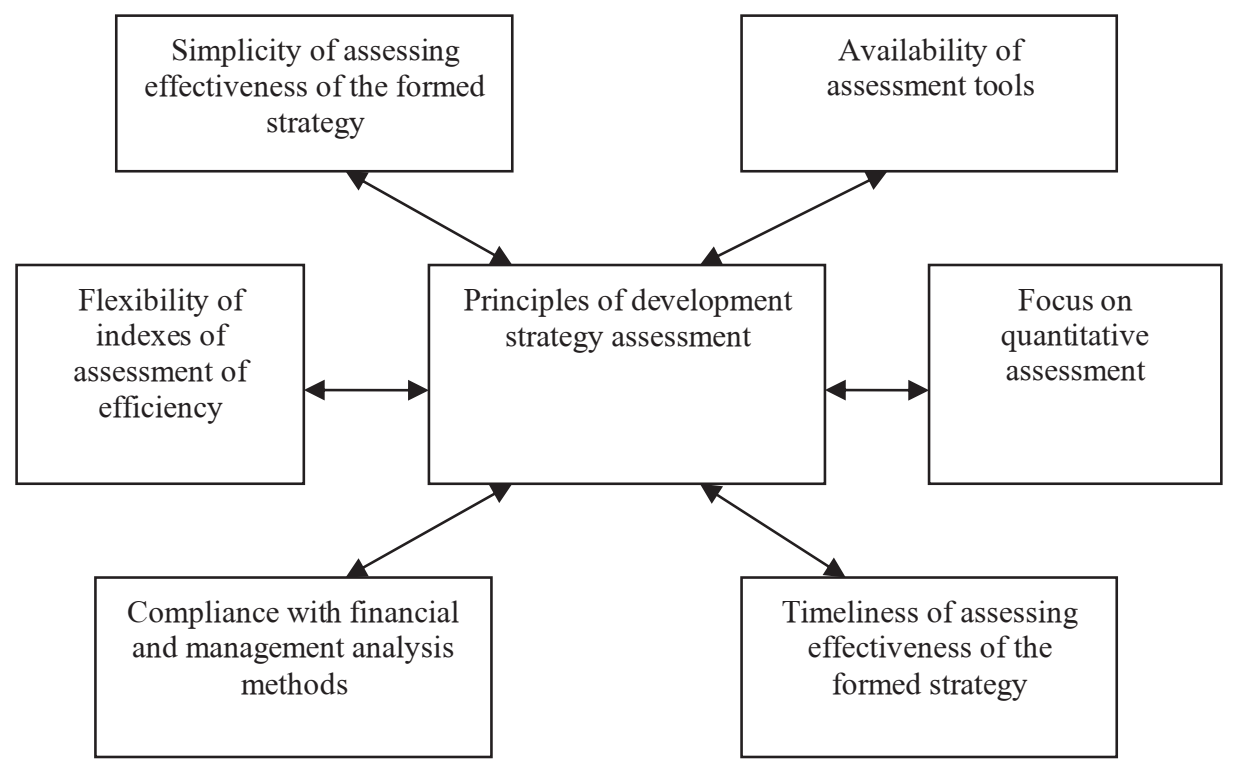

Fig. 2. Principles of development strategy assessment.

The content of these principles should be considered:

1. Simplicity of assessment. The simplest forms and methods for assessing effectiveness of implementation of the formed strategy require less effort of specialists involved in assessment and, accordingly, are the most economical.

2. Availability of assessment tools. Tools for assessing effectiveness of implementation of the formed strategy should be provided with sufficient qualifications of specialists and technical support on the part of information management. 
3. Flexibility of efficiency indexes. The indexes for assessing the development strategy should be complex and take into account a set of all strategic quantitative indexes. Thus, a complex index can include any strategic targets..

4. Focus on quantitative assessment. Usefulness of management actions increases significantly if complex indexes for assessing the development strategy are expressed in specific quantitative values. This is all the more important because quantitative assessment allows objective comparison of alternative options of strategies for production and economic development.

5. Compliance with management analysis methods. In the process of assessing effectiveness of the formed strategy, it is necessary to focus on a set of methods and indexes used in the practice of management analysis.

6. Timeliness of assessing effectiveness of the formed strategy. Such timeliness should consist in early warning of deviations of strategic indexes for the timely elimination of such deviations before they become threatening $[5,6]$.

On the basis of the above principles, the methodology for assessing the development strategy is proposed, which consists in calculating the index characterizing achievement of set strategic goals. An estimated development index is proposed as such an index that takes into account key strategic parameters.

This index, in accordance with the set strategic goals, should take into account an entire set of target strategic indexes.

Two algorithms for calculating the estimated development index are proposed. The first is due to the fact that the estimated development index, in accordance with the goals, should take into account the relative indexes of the dynamics of target strategic indexes and be calculated using the formula:

$$
E D I=\sqrt[n]{T_{1} * T_{2} * T_{3} * \ldots * T_{n}}
$$

where $T_{1}, T_{2}, T_{3} \ldots T_{n}$ - relative indexes of the dynamics of strategic indexes (growth rates).

In this case, the nature of the relationship between the estimated development index and target strategic indexes should be taken into account: the growth of some strategic indexes has a negative effect on the change in the estimated development index, and, on the contrary, their decrease has a positive effect on the change in the estimated development index. Such indexes should be presented in the form of an inverse relationship - "1 / T".

For example, in relation to a specific organization, strategic targets include dynamic indexes, namely:

- the coefficient of growth of production costs;

- the coefficient of growth of the volume of sales of products;

- the coefficient of growth of net profit;

- the coefficient of growth of share of the organization in the industry market of the region;

- the coefficient of growth rate of raw materials use.

In this case, the dynamic index of production cost should be presented in the form of 1 / $\mathrm{Tc}$, since, obviously, the growth of production cost has a negative impact on the change in the estimated development index.

In accordance with the first algorithm, the estimated development index is recommended to be calculated using the following formula:

$$
E D I=\sqrt[5]{1 / T_{c} * T_{v} * T_{n p} * T_{s h} * T_{r m}}
$$

where:

$\mathrm{T}_{\mathrm{c}}-$ the coefficient of production cost;

$\mathrm{T}_{\mathrm{v}}-$ the coefficient of growth of volume of sales of products; 
$\mathrm{T}_{\mathrm{np}}-$ the coefficient of growth of net profit;

$\mathrm{T}_{\mathrm{sh}}$ - the coefficient of growth of share of the organization in the industry market of the region;

$\mathrm{T}_{\mathrm{rm}}$ - the coefficient of growth rate of raw materials use.

According to the calculation results, the data are systematized and presented in table 2.

Thus, in the studied strategic period, the estimated development index will be 1.08 , which will indicate achievement of strategic goals, and, consequently, economic efficiency of the developed strategy.

Table 2. Dynamics of the estimated development index.

\begin{tabular}{|c|c|c|c|c|c|c|}
\hline \multirow{2}{*}{ Strategic indexes } & \multicolumn{7}{|c|}{ Growth rates of indexes (chain). coef. } \\
\cline { 2 - 7 } & $\mathbf{2 0 1 7}$ & $\mathbf{2 0 1 8}$ & $\mathbf{2 0 1 9}$ & $\mathbf{2 0 2 0}$ & $\mathbf{2 0 2 1}$ & $\mathbf{2 0 2 2}$ \\
\hline $\begin{array}{c}\text { Revenue from the sale of } \\
\text { products }\end{array}$ & 1.27 & 0.99 & 1.1 & 1.1 & 1.1 & 1.1 \\
\hline Production cost & 1.19 & 1.20 & 1.16 & 1.09 & 1.09 & 1.09 \\
\hline Net profit & 0.24 & 3.24 & 1.05 & 1.15 & 1.15 & 1.15 \\
\hline $\begin{array}{c}\text { Share of the organization } \\
\text { in the industry }\end{array}$ & 1.17 & 1.18 & 1.15 & 1.17 & 1.17 & 1.17 \\
\hline Raw material usage rate & 1.00 & 1.02 & 1.01 & 1.10 & 1.10 & 1.10 \\
\hline $\begin{array}{c}\text { Estimated development } \\
\text { index }\end{array}$ & 0.74 & 1.33 & 1.03 & 1.08 & 1.08 & 1.08 \\
\hline
\end{tabular}

This index should be used as an indicator of effectiveness of the developed strategy and achievement of strategic goals.

This index should be used as an indicator of effectiveness of the developed strategy and achievement of strategic goals.

However, the calculation of the estimated development index, taking into account the combination of positive trends of all strategic indexes, can be presented in an alternative form, while its value should be more than 1 . If this condition is met and strategic goals are achieved, therefore, the developed strategy can be considered effective.

This is the second algorithm for calculating the estimated development index, which is proposed to be calculated using the formula:

$$
E D I=\frac{\sqrt[n]{T p_{1} * T p_{2} * \ldots * T p_{n}}}{\sqrt[k]{T n_{1} * T n_{2} * \ldots * T n_{k}}}
$$

where

$T p_{1}-T p_{n}$ - strategic indexes, growth of which has a positive effect on the change in the estimated development index;

$T n_{1}-T n_{K}$ - strategic indexes, growth of which has a negative effect on the change in the estimated development index.

Based on the above formula, the estimated development index was calculated, the values of which are presented in the table 3 .

Table 3. Dynamics of the estimated development index.

\begin{tabular}{|c|c|c|c|c|c|c|}
\hline \multirow{2}{*}{ Strategic indexes } & \multicolumn{7}{|c|}{ Growth rates of indexes (chain). coef. } \\
\cline { 2 - 7 } & $\mathbf{2 0 1 7}$ & $\mathbf{2 0 1 8}$ & $\mathbf{2 0 1 9}$ & $\mathbf{2 0 2 0}$ & $\mathbf{2 0 2 1}$ & $\mathbf{2 0 2 2}$ \\
\hline $\begin{array}{c}\text { Revenue from the sale of } \\
\text { products }\end{array}$ & 1.27 & 0.99 & 1.1 & 1.1 & 1.1 & 1.1 \\
\hline Net profit & 0.24 & 3.24 & 1.05 & 1.15 & 1.15 & 1.15 \\
\hline $\begin{array}{c}\text { Share of the organization } \\
\text { in the industry }\end{array}$ & 1.17 & 1.18 & 1.15 & 1.17 & 1.17 & 1.17 \\
\hline Production cost & 1.19 & 1.20 & 1.16 & 1.09 & 1.09 & 1.09 \\
\hline
\end{tabular}




\begin{tabular}{|c|c|c|c|c|c|c|}
\hline Raw material usage rate & 1.00 & 1.02 & 1.01 & 1.10 & 1.10 & 1.10 \\
\hline $\begin{array}{c}\text { Estimated development } \\
\text { index }\end{array}$ & 0.60 & 1.30 & 0.94 & 1.37 & 1.37 & 1.37 \\
\hline
\end{tabular}

The results of the calculations of the value of the estimated development index give grounds to conclude that in the designated strategic period, the estimated development index should be 1.37, which is more than 1 , and this indicates achievement of strategic goals, and, consequently, economic efficiency of the developed strategy.

After the diagnostics of effectiveness of the formed development strategy, it is necessary not only to identify the presence of deviations of the obtained results from strategic goals and to assess them quantitatively, but also to determine the nature of such deviations.

The nature of the identified deviations, caused by certain changes in individual target strategic indexes, can be either positive or negative. If the deviation of the estimated development index from the normative one is negative, i.e. the index deteriorates significantly, and then the process of identifying the reasons for such deviations should be carried out.

Reasons for deviations can be non-formalized and formalized. Non-formalized reasons for deviations can be subjective and objective.

Identification of formalized reasons, i.e. reasons that can be quantified, should be carried out using factor analysis.

After the reasons for deviations of the estimated development index from the norm have been identified, a decision is made on the need to adjust the target strategic indexes and ways to achieve them.

Adjustment can be carried out in the following cases:

-in case of unforeseen changes in the factors of the external business environment of the organization functioning, accumulating significant threats to implementation of the strategy of economic development, the impact of which cannot be fully eliminated;

-in case of unforeseen changes in the factors of the external environment of the organization functioning, which create quite significant additional opportunities for economic development of the organization;

- when changing, namely, increasing the internal financial and economic potential of the organization due to the additional effect obtained as a result of a fairly successful implementation of strategic changes;

- when changing rather seriously determined goals of the organization economic development strategy.

The developed mechanism allows giving express assessment of the development strategy, which is important in the process of strategic management of the development of organizations. To implement it, rather accessible tools of economic analysis are used, which, as a rule, are mastered by majority of modern managers.

\section{References}

1. N.S. Otvarukhina, V.R. Vesnin, Modern strategic analysis 25 (2020)

2. A.N. Fomichev, Strategic management 18 (2018)

3. L.N. Ridel, Enterprise development strategy, 30 (2018)

4. E.V. Petrova, Bulletin of ISTU 1, 60 (2014)

5. E. Anoshkina, E. Markovskaya, A. Mottaeva, As. Mottaeva, E3S Web of Conferences 210, 13022 (2020) https://doi.org/10.1051/e3sconf/202021013022

6. E.V. Petrova, Science and economics 2, 42 (2012) 